\title{
Professora e pesquisadora: um encontro na sala de aula
}

\author{
Laura Noemi Chaluh*
}

Resumo: Estive inserida como pesquisadora em uma escola de Ensino Fundamental da Rede Municipal de Campinas-SP de 2003 a 2005. Opto, neste trabalho, por narrar o meu encontro em sala de aula com uma professora cujo trabalho acompanhei no ano letivo de 2004. Esta escolha está motivada por eu ter sido convidada por essa professora para participar semanalmente das suas aulas e pelas inquietações surgidas a partir do diálogo por nós estabelecido. Problematizo o lugar de uma pesquisadora quando entra na sala de aula, as expectativas da professora diante da presença da pesquisadora na sua sala e os sentidos produzidos pelos alunos com a presença de uma outra professora. A partir de uma pesquisa de orientação sócio-histórica, trago para reflexão a questão da alteridade e do diálogo, a fim de pensarmos na formação de professores e pesquisadores.

Palavras-chave: formação; pesquisa; alteridade.

\section{Teacher and researcher: contact in a classroom}

Abstract: During the period from 2003 to 2005 I worked as a researcher in an elementary school from the Municipal Education Network of Campinas. This paper is about my contact with a teacher whose classes I attended during the school year of 2004. This choice was motivated by this teacher's invitation to participate in her classes on a weekly basis and by the doubts that arised from our dialogue. The condition of a researcher in a classroom, a teacher's expectations in the presence of a researcher in her classroom and the students' senses in the presence of another teacher are questioned. From a socio-historical research, the alterity and the dialogue issues are discussed to foster a reflection about teachers' and researchers' education.

Key words: teacher education; research; alterity.

\section{Relembrando os percursos...}

O presente texto tem relação com o projeto de doutorado a partir do qual me propus a acompanhar os espaçostempos de reflexão coletiva instituídos em uma escola de Ensino Fundamental da Rede Municipal de Ensino de Campinas (2001-2004) e deles participar. Nesse sentido, propus-me a explicitar a política pública de formação continuada da Secretaria Municipal de Educação

* Doutora em Educação. Pesquisadora do Grupo de Estudos e Pesquisas em Educação Continuada (Gepec) da Faculdade de Educação da Unicamp, Campinas, SP, Brasil.chaluh@uol.com.br 
(SME) desse município e evidenciar como ela era recriada pelas professoras no cotidiano da escola. Assim, as primeiras inquietações tinham a ver com o fato de compreender o processo de constituição de um grupo de professoras na escola, sabendo que a política pública de formação dessa Secretaria favorecia o trabalho coletivo nos encontros de formação na escola.

Para isso, inseri-me como pesquisadora em uma escola de Ensino Fundamental dessa rede desde agosto de 2003 até dezembro de 2005. Acompanhei dois espaçostempos de formação instituídos: O Trabalho Docente Coletivo (TDC) e o Grupo de Reflexão sobre Letramento e Alfabetização (GA).

O TDC é um espaço formativo, de reflexão coletiva, realizado durante duas horas-aula semanais consecutivas, coordenadas pelo/a orientador/a pedagógico/a ou, na sua ausência, por um/a professor/a eleito/a pelo grupo como coordenador/a da reunião. O GA surgiu no ano letivo de 2004, quando a SME possibilitou a constituição de um Grupo de Trabalho em cada uma das escolas dessa rede, com o intuito de que as professoras refletissem sobre a especificidade da alfabetização. Elas teriam "duas horas aulas a mais para fazer um trabalho de formação e ajudar a reduzir o número de retenções de alunos com dificuldade de aprendizado" (SME, 2004).

A partir do ano letivo de 2004, o orientador ${ }^{1}$ da pesquisa sugeriu-me entrar na sala de aula e acompanhar o trabalho pedagógico de uma professora, observando as possíveis relações entre o trabalho coletivo nos grupos instituídos nessa escola e o trabalho pedagógico desenvolvido pela professora que eu iria acompanhar na sala de aula.

Optei por perguntar à professora, que atuava na 4a. série, se ela aceitaria a minha presença na sua sala. Sua resposta foi positiva. Nesse momento, a professora ${ }^{2}$ Mônica, que atuava em uma 2a. série, ao saber que eu estaria na sala de aula de uma colega, convidou-me a entrar na sua sala e eu aceitei. Dessa forma, acompanhei o trabalho realizado em duas turmas: na $4^{\text {a }}$. série e na $2^{\mathrm{a}}$., embora este relato se ocupe especificamente desta última, cuja professora era uma profissional "nova", recém-formada e, já no início, instigou-me, quando me perguntou: "Você vai vir para pesquisar ou para me ajudar?".

A pergunta da professora e outras questôes que eu mesma comecei a me formular ao viver a escola levaram-me a compreender o para quê e o porquê de fazer pesquisa na e com a escola. Afirmo que só no momento em que vivi a relação com os outros é que percebi a importância da alteridade (Bakhtin, 1992) como fundamento de todo o desenvolvimento da minha pesquisa: esta ganhou

I. O orientador da pesquisa foi o Prof. Dr. Guilherme do Val Toledo Prado.

2. Agradeço à professora que me permitiu tornar públicas as falas que fazem referência à sua pessoa. 
força quando, a partir do reconhecimento da alteridade, começou a ter sentido para mim como pesquisadora. Foi assim que assumi a pesquisa de orientação sócio-histórica (Freitas, 2003a; 2003b; Amorim, 2004), o que significa conceber a pesquisa como uma relação, como diálogo e também considerar a importância dos outros como sujeitos que, junto comigo, iriam caminhar em um processo. Isso implicava pensar que, na relação com os outros, tanto eu como os outros nos modificamos mutuamente, constituindo-nos no encontro.

Neste texto, opto por narrar o meu encontro com Mônica, professora da 2 a. série, e seus alunos no ano letivo de 2004. A escrita deste trabalho é apresentada em forma de narrativa segundo uma perspectiva benjaminiana. Sei que, ao narrar, estou me expondo, o que gera em mim medos e inseguranças. Como diz Benjamin (1996), nós sentimos "embaraço" quando somos solicitados a narrar alguma coisa. Tomo para mim essa sensação de "embaraço" e ainda com ela me proponho um desafio, porque narrar é recuperar e manter "a faculdade de intercambiar experiências" (Benjamin, 1996, p. 198). Segundo Larrosa (2004a), "a experiência [...] é o que nos passa, [...] o que nos acontece", o que nos toca. Este mesmo autor considera que podemos compartilhar acontecimentos, mas a experiência de cada um de nós - "o que nos passa" - será diferente. Levando em consideração o sentido de experiência de Larrosa (2004a) é que pretendo explicitar "o que me passou", ao ser convidada por essa professora a entrar na sala de aula como pesquisadora. Resgato, assim, a importância de narrar, valorizar e socializar as nossas experiências, assumindo a minha responsabilidade, para que a arte de narrar não seja extinta, preocupação colocada por Benjamin (1996).

Ainda, neste texto, procuro pistas e sinais (Ginzburg, 1989) que me permitam compreender os sentidos da presença de uma pesquisadora na sala de aula. Quando Ginzburg (1989), a partir do paradigma indiciário, traz as noções de pistas, sinais e indícios, considera que esses são detalhes que, no acontecimento, apresentam-se como secundários e irrelevantes, mas que têm uma importância fundamental no momento de compreender uma determinada realidade. Assim, procurar pistas que mostrem os sentidos produzidos pela professora Mônica, pelos seus alunos e pela pesquisadora em relação à presença desta última na sala de aula é uma tentativa de compreender quais as implicações dessa presença no espaço escolar.

\section{A entrada na sala de aula da professora}

A professora convidou-me a entrar na sua sala de aula, mas, na minha memória, ecoava o seu questionamento: "Você vai vir para pesquisar ou para me ajudar?”. 
Ela tinha solicitado minha ajuda, mesmo sabendo do meu olhar de pesquisadora ao entrar na sua sala. Uma questão que começou a me preocupar foi como ocupar o lugar de uma pesquisadora que ajuda. O que seria ajudar a professora? Ser uma pesquisadora que ajuda implicava pensar em uma pesquisadora comprometida tanto com a professora, como com os seus alunos, com a escola.

A proposta da professora, no começo, foi que eu ficasse com duas crianças que ela queria que eu ajudasse especialmente. Os demais alunos também começaram a solicitar a minha ajuda: "Professora, você me ajuda? Professora, fica comigo! Senta aqui!". Foi assim que fui aprendendo, no movimento com os alunos, quais os possíveis caminhos para acompanhar o trabalho deles. Estar na sala de aula implicou estar atenta às necessidades $e$ às solicitaçóes dos alunos e permitiu-me perceber o quanto ficou fácil e tranqüilo, para os alunos, estar na sala de aula com duas professoras.

No começo, a minha ajuda consistia em acompanhar o trabalho desenvolvido por alguns dos alunos, compartilhar algumas atividades com as crianças, fazer uma proposta para trabalhar alguma atividade, acompanhar o grupo na hora da biblioteca, ler contos com os alunos, escutar a leitura deles, acompanhar a escrita de alguns...

Eu comecei a interrogar-me se minha ajuda e minha tarefa consistiriam em acompanhar esses alunos que a professora me havia indicado. $\mathrm{O}$ compromisso com a professora implicaria abordar com ela as questôes observadas por mim e que tinham a ver com a sua prática? E, no caso, como dizer? Como iniciar esse diálogo, sem que a "professora nova" sentisse que era eu que tinha o conhecimento do ser professora? Mas que, ao contrário, percebesse que eu estava no lugar de uma professora cuja intenção era, a partir do que conseguia enxergar participando da complexidade da sala de aula, ajudar a outra?

Certo dia, a professora Mônica perguntou-me quando é que poderíamos conversar. Marcamos nosso primeiro encontro no mês de abril. Nesse dia, conversamos sobre suas inquietações e dúvidas a respeito da sua prática e, também, de minha inquietação sobre uma atividade proposta por ela em relação a fazer uma cópia. A professora apontou como suas preocupaçôes a dinâmica do grupo de alunos, a rotina da/na sala de aula, a autonomia dos alunos, as arbitrariedades (im)postas na escola.

Esse encontro foi uma marca para mim, pois aprendi a ter com a professora uma interlocução em que eu consegui mostrar certas coisas para, juntas, refletirmos sobre isso, e não apenas para dizer se estava certo ou errado. Esse foi um momento privilegiado, já que tive a oportunidade de estar com uma professora que tinha me convidado a entrar na sua sala de aula e, além disso, chamava-me para conversar. $\mathrm{O}$ fato de eu ter sido professora dava-me legitimidade para eu 
expor essas coisas para ela? O fato de eu ser pesquisadora legitimava-me a dizerlhe essas coisas? Será que a legitimidade estava estabelecida pelo fato de ela ter me convidado e de eu estar falando do lugar de professora, nessa relação de uma professora que dialoga com outra?

A professora Mônica foi um grande desafio para mim, como pesquisadora. Penso que ela, o meu outro na escola, provocou-me, fez-me refletir sobre o meu lugar de professora e de pesquisadora na escola.

\section{Pensando juntas uma proposta}

No Grupo de Reflexão sobre Alfabetização (GA) com as professoras de 1a. e 2a. séries, a orientadora pedagógica e a diretora, surgiu a necessidade de aprofundar o conhecimento de alguns conceitos sobre o número, o sistema de numeração decimal, o trabalho com agrupamentos em diferentes bases. Foi em um desses encontros que propus ao grupo fazer algumas atividades com material concreto e elaborar alguns aspectos teóricos que as estavam embasando, pensando que, posteriormente, as professoras poderiam ter elementos para trabalhar esses aspectos com os seus alunos. O trabalho foi planejado para dois encontros e, posteriormente, foi ampliado, quando fiquei responsável por coordenar outros encontros a partir da leitura de dois volumes dos textos Atividades matemáticas ${ }^{3}$ para as 1 as. e 2as. séries - sugeridos pela orientadora pedagógica - , com a finalidade de analisar os conteúdos e os objetivos de Matemática para essas séries e as possíveis formas de trabalhar com os alunos. Após as oficinas de Matemática que aconteceram no GA, a professora Mônica comentou que tinha algumas dificuldades em fazer uma proposta específica para sua turma. Em um dos nossos encontros posteriores ${ }^{4}$ fora da sala de aula, pensamos juntas e planejamos uma proposta para desenvolver com os seus alunos na sala de aula, tendo como objetivo o trabalho com diferentes bases.

Durante dois dias trabalhamos juntas na sala de aula com as atividades que tínhamos planejado realizar com os alunos. Uma das alunas da professora Mônica registrou por escrito o trabalho com as bases que juntas tínhamos desenvolvido na sala de aula. Essa aluna escreveu: "ela [falando da pesquisadora] nos ensinou matemática brincando, com os palitos e os dados".

No fim do ano, eu quis saber dos sentidos produzidos pelos alunos em relação à presença de uma outra professora na sala de aula. Ficou evidente, nos registros, que eu ia à sala de aula para ajudar os alunos e a professora. Apresento alguns dos registros dos alunos:

3. São Paulo (Estado). Secretaria da Educação. Coordenadoria de estudos e Normas Pedagógicas, Atividades matemáticas: ciclo básico. São Paulo: SE/CENP, 1991. volumes I e 2.

4. Posteriormente, comentarei sobre os "encontros fora da sala de aula" com a professora. 


\begin{abstract}
"Eu gosto de ter duas professoras porque eu aprendo mais".
"Eu gostei muito de ter duas professoras porque, quando a Mônica tá trabalhando, ela [a pesquisadora] pode nos ajudar, ela ajuda a professora".

"Uma professora ensina e a outra ajuda, é muito legal".

"É melhor para ensinar, para ensinar os alunos a escrever e ler, a fazer prova e ajudar em outras coisas também, ajuda a outra professora".

"Gostei de ter duas professoras do meu lado para ajudar a classe, a professora Mônica".

"A gente aprende mais [...] a turma aprende mais".

"Porque ensinam mais, é mais legal, Ensinam mais tempo. É muito divertido. É mais legal do que uma só”.

"Porque quando a professora Mônica sai, ela [a pesquisadora] fica com a gente; quando não tem, a professora sai, nós ficamos fazendo bagunça”.
\end{abstract}

Encontros na sala de aula. Os alunos apontando a importância da presença de outra professora, que ajuda e, com isso, possibilita "aprender mais". Professora e pesquisadora, apesar de todos os desafios e conflitos gerados, buscando caminhos para pensar na aprendizagem das crianças e oportunizar o aproveitamento de todos os alunos.

\title{
Em busca de um momento de reflexão conjunta
}

Ao viver a escola, procurei por referenciais que dessem suporte a meu serestar pesquisadora ali, considerando as questôes que iam surgindo nos acontecimentos e na vida da escola.

Segundo Freitas (2003b), a abordagem sócio-histórica é compreendida a partir de Lev Vygotsky, com a teoria social da construção do conhecimento, e de Mikhail Bakhtin, com a teoria enunciativa da linguagem. A autora traz os aportes de Vygotsky e Bakhtin, já que considera que eles apresentam uma mudança de paradigmas, indicando que suas teorias, fundamentadas no materialismo histórico dialético, foram produzidas a partir das críticas aos reducionismos das concepçóes empiristas e idealistas. As teorias elaboradas por esses dois autores foram construídas numa perspectiva de superação dialética de modelos existentes. Assim, Freitas (2003b) reflete acerca das contribuições que as perspectivas desses autores podem trazer para a pesquisa educacional.

Dialoguei com Amorim (2002; 2003; 2004), Freitas (1997; 2002; 2003a; 2003b), Geraldi (2003a; 2003b; 2005), Jobim e Souza (1997), que me permitiram problematizar a atividade de pesquisar a partir de uma perspectiva fundamentada nas formulações teóricas de Mikhail Bakhtin, no trato específi- 
co com a questão da alteridade.

Apoiando-se em Bakhtin, Freitas (2003a) reflete sobre as perspectivas abertas pela teoria enunciativa da linguagem a partir de uma abordagem sóciohistórica, especialmente para os trabalhos de pesquisa no campo da educação. A autora enfatiza que, ao considerar a perspectiva sócio-histórica, podemos abrir caminhos para uma outra forma de produzir conhecimento no campo das ciências humanas. Segundo Freitas (2003a), o pesquisador é um dos instrumentos da pesquisa, além de ser parte da investigação. Nesse sentido, ele pode compreender a partir do lugar social no qual se encontra e a partir das relaçôes subjetivas que estabeleceu com os sujeitos da pesquisa. Assim, tanto pesquisado como pesquisador participam juntos da investigação e ambos refletem, aprendem e se ressignificam no processo de pesquisa.

Para pensar na relação sujeito e pesquisador, atrelada à questão da ressignificação de ambos no processo da pesquisa, trato da possibilidade que tive de vivenciar isso no vínculo estabelecido com a professora Mônica. No mês de agosto daquele ano, quis saber em que medida a professora estava sentindo minha "ajuda". Dentre as considerações apontadas por ela, gostaria de resgatar: "Nós não estamos refletindo juntas". A professora estava solicitando "um tempo" específico para dialogar sobre as suas inquietações, além das conversas informais mantidas tanto dentro da sala de aula como ao final de cada aula ou juntas, na sala de professores.

Em função disso, a partir desse momento, começamos a ter encontros fora da sala de aula para conversar sobre sua prática, suas e minhas dúvidas, suas e minhas inquietações/angústias e as questôes que eu conseguia enxergar. Importante foi poder reconhecer essa necessidade de refletir juntas, e a professora sugeriu termos esses encontros todas as sextas-feiras possíveis na hora da aula de Educação Física. Foram ao todo sete encontros. Paralelamente à construção desse "nosso espaço" de diálogo, decidi iniciar a escrita de cartas para a professora. A prática de "escrever para o outro"s já tinha sido realizada por mim em outro momento e eu acreditava que essa seria uma outra instância importante para mantermos um diálogo.

Foi assim que comentei com a professora que iria fazer um retorno do que eu conseguia enxergar estando na sua sala de aula. Antes de enviar a primeira carta, encaminhei-lhe um e-mail no qual apontava a minha crença em relação à potencialidade que um outro olhar poderia ter para a nossa prática e resgatei episódios de minha experiência como professora quando com um outro (cole-

5. Quando estagiária de uma disciplina de um Curso de Pedagogia, decidi fazer um relato por escrito de minhas observações e impressões (pensamentos, reflexões, sensações, dúvidas, interrogações) para que o professor que ministrava essa disciplina a elas tivesse acesso (ver Chaluh, 2005). 
gas, professoras, diretora, vice-diretora) podia dialogar sobre o meu grupo de alunos. A resposta da professora Mônica foi:

Agora, para mimé muito bom ter esse outro olhar... Principalmente porque você já tem bastante experiência em sala de aula - écerto que com outros alunos, outra realidade, outras necessidades. Mas, é sempre um olhar de construção e isso faz com que eu me sinta muito à vontade com você (e-mail encaminhado pela professora no dia 29 junho de 2004, destaques meus).

Após ter recebido as primeiras cartas, a professora encaminhou alguns $e$ mails para mim, apontando o que essas escritas estavam provocando nela. Enviei, ao todo, nove cartas para a professora e uma carta para o seu grupo de alunos. Ali eu narrava o movimento do que tinha acontecido nas aulas das quais eu participava. Também retomava as nossas conversas e colocava as minhas inquietaçōes, a partir de algumas atitudes da professora que, para mim, que sabia dos seus pensamentos e de seu posicionamento com relação à educação e à escola, eram "estranhas".

As cartas foram importantes para a professora, segundo ela comentou. Apresento alguns escritos da professora que trago aqui como pistas, na pretensão de encontrar alguns sentidos no diálogo que iniciávamos a partir da troca de cartas e e-mails. Algumas falas da professora:

Acabo de ler suas cartas... Estou emocionada. A dinâmica da escola e da vida acaba promovendo na gente um esquecimento daquilo que é significativo.

Eu tinha pouca, quase nenhuma lembrança dessas situaçôes que você narra. Em alguns momentos, nem mesmo conseguifazer relação com o ocorrido, mas penso que - novamente - esse olhar externo tenha muita importância para que eu me encontre nesse movimento... (e-mail encaminhado pela professora no dia 14 de setembro de 2004, destaques meus).

Suas cartas têm se mostrado muito importantes para mim.

Eu me comprometo em respondê-las, com certeza. Só que, no momento, ainda estou impedida pelo tempo. Mas, não deixarei de fazê-lo.

Acho que essas cartas que possamos trocar ajudarão nessa construção conjunta do meu fazer educativo e da sua pesquisa ( $e$ mail encaminhado pela professora no dia 22 de setembro de 2004, destaques meus).

Nós, às vezes, temos alguns mal entendidos por conta da comunicação-tanto da língua, como do tempo...

Algumas interpretaçôes suas não contemplam a dinâmica do processo, porque você não o acompanha todos os dias... Mas isso não é 
buraco. A pesquisa nunca dá conta da realidade! Ela pode, quando muito, interpretar um ou outro aspecto. Nem por isso deixa de ser importante, de ampliar nossas possibilidades de ler o próprio trabalho (e-mail encaminhado pela professora no dia 09 de novembro de 2004, destaques meus).

Pistas que encontro nas falas da professora: "um olhar de construção e isso faz que eu me sinta muito à vontade com você"; "mas penso que - novamente - esse olhar externo tenha muita importância para que eu me encontre nesse movimento"; "acho que essas cartas que possamos trocar ajudarão nessa construção conjunta do meu fazer educativo e da sua pesquisa"; "de ampliar nossas possibilidades de ler o próprio trabalho". A questão do "olhar" aparece com força em suas palavras. Ela apontou a importância do olhar do outro, do retorno que o outro me dá, indicando que essa relação possibilitou que ela pudesse entrar em um movimento para compreender o seu próprio trabalho.

As cartas também foram importantes para mim, porque, a partir da escrita, conseguia amarrar alguns sentidos: distanciar-me, olhar de um lugar exterior; acredito que o momento da escrita tenha sido o momento do "desdobramento de olhares" do qual nos fala Amorim (2003), quando faz referência à exotopia. Momento de escrita que me possibilitava olhar para a professora e sua prática, mostrando coisas que ela mesma não conseguia enxergar e que eu, a partir de um lugar exterior, conseguia. A escrita possibilitou-me olhar para mim mesma dentro desse movimento.

Amorim (2003), ao tratar da exotopia, desdobramento de olhares a partir de um lugar exterior, considera que esse lugar exterior permite que se veja do sujeito algo que ele próprio não pode ver: "a obra de arte é lugar de tensão porque, entre o eu e o outro, entre o retrato que faço de alguém e o retrato que ele faz de si mesmo, há sempre uma diferença fundamental de lugares e, portanto, de valores." (p. 14).

Estar no lugar de pesquisadora na escola permitiu-me estar dentro e fora, tanto dos grupos como das situações acontecidas com as professoras na sala de aula. Segundo Bakhtin (1992), ao falar em excedente de visão, temos que nos identificar com o outro e ver o mundo através do seu sistema de valores:

devo colocar-me em seu lugar, e depois, de volta ao meu lugar, contemplar seu horizonte com tudo o que se descobre do lugar que ocupo fora dele; devo emoldurá-lo, criar-lhe um ambiente que o acabe, mediante o excedente de minha visão, de meu saber, de meu desejo e de meu sentimento (p. 45).

Ter como supostos teóricos a alteridade e a exotopia no desenvolvimento da pesquisa implica considerar esta como uma relação entre sujeitos (Freitas, 2003a; 
2003b). Assim, construir e desenvolver uma pesquisa a partir de uma perspectiva dialógica deixa em evidência o papel central que assume a interação entre os sujeitos que dela participam. Nesse sentido, a professora Mônica e eu, pesquisadora - ambas sujeitos da pesquisa —, a partir do diálogo e da interlocução, tivemos a possibilidade de refletir sobre nós e nossas práticas, sejam as práticas da professora na sala de aula, ou as de pesquisa promovidas na escola pela pesquisadora.

\section{No encontro, o sentido da formação}

Neste ponto proponho-me a aprofundar a perspectiva de pesquisa como uma relação entre sujeitos, considerando suas implicaçóes. Nesse sentido, acho que o encontro da professora com a pesquisadora possibilitou pensar na formação com uma nova concepção que ganhou outros significados quando foi possível compreender que, no encontro com o outro, este se apresenta como desencadeador de um processo formativo. Assim, foi possível pensar na formação como uma relação de provoca-ação, ou pensar na relação com o outro como uma provoca-ação formativa (Chaluh, 2008).

Para tratar da relação da pesquisa atrelada à formação, remeto-me à frase da professora Mônica, "Você vai vir para pesquisar ou para me ajudar?", porque acredito que essa fala, assim como tantas outras que me disseram as professoras, levou-me a refletir acerca da ajuda e da colaboração que uma pesquisadora poderia oferecer à escola, mobilizando, assim, meu processo formativo como pesquisadora. Segundo a professora, o olhar do outro, no caso, a pesquisadora, possibilitou que ela também entrasse em um movimento para compreender o seu próprio trabalho.

Para tratar a questão da formação pensada como uma relação de provocaação, dialogo com Bakhtin (1993) e Larrosa (2006), autores que me permitem aprofundar a reflexão acerca desse assunto.

Bakthin (1993) considera que todo ato é ético e estético, e aqui problematizo a questão estética. Para o autor, a reflexão estética da vida viva não é, por princípio, a auto-reflexão da vida em movimento, pois pressupõe um outro sujeito, um sujeito da empatia, um sujeito situado do lado de fora,

Um momento essencial (ainda que não o único) da contemplação estética é a identificação (empatia) com um objeto individual da visão - vê-lo de dentro de sua própria essência. Esse momento de empatia é sempre seguido pelo momento de objetivação, isto é, colocar-se do lado de fora da individualidade percebida pela empatia, um separar-se do objeto, um retorno a si mesmo (p. 15). 
Segundo Bakhtin (1993), quando essa consciência se volta para si mesma, "dá forma, de seu próprio lugar, à individualidade captada de dentro, isto é, enforma-a esteticamente como uma individualidade unitária, íntegra e qualitativamente original.” (p. 15). Nesse sentido, os momentos estéticos têm significado e são realizados por aquele que se identifica, aquele que está situado do lado de fora.

Convém lembrar que a contemplação estética do objeto implica um processo de empatia e objetivação-formação. Isso significa que, após a contemplação do objeto, é preciso que eu retorne sobre mim mesma para, dessa forma, entrar em um processo de objetivação-formação. Esse processo caracteriza-se por ser o momento de dar um sentido a essa contemplação estética, ou seja, dar uma possível compreensão do outro, a partir do ato, no mundo da cultura. Por isso, após a contemplação estética, saímos enriquecidos, somos outros após o encontro.

$\mathrm{Na}$ escola, foi possível que a pesquisadora contemplasse as professoras e que estas contemplassem a pesquisadora. Foi a partir dessas relaçôes que, ao sair do mundo da empatia, fomos transitando para o mundo da objetivação-formação, para o mundo da cultura. É essa passagem que nos permite construir uma possível interpretação acerca do outro, dando a este um acabamento estético a partir do nosso lugar exterior e singular.

Aprofundando a concepção da formação como uma relação de provocaação, estabeleci um diálogo com Larrosa (2006). O autor, a partir de outra perspectiva, considera que há uma relação constitutiva entre a idéia de experiência e a idéia de formação.

Para Larrosa (2006), o resultado da experiência é a formação ou a transformação do sujeito da experiência. $\mathrm{O}$ autor supõe que a experiência tenha três princípios: o primeiro, princípio da subjetividade, supõe que a experiência seja sempre subjetiva e o sujeito da experiência seja capaz de deixar que alguma coisa aconteça com suas palavras, suas idéias, sentimentos, etc.; o segundo, princípio da reflexividade, supõe que a experiência seja o "que me passa" (sendo o "me" um pronome reflexivo) e supóe um movimento "de ida e de volta": o movimento "de ida" indica que a experiência supõe um movimento de exteriorização, de saída de mim mesmo, ao encontro do acontecimento; após o movimento de exteriorização, dá-se o movimento "de volta", quando regresso a mim mesmo e então percebo que essa experiência (o encontro com o acontecimento) "me afetou", ou seja, esse acontecimento teve um efeito em mim, no que eu sou, no que penso, sinto, quero, etc.; o terceiro, "o princípio de transformação", supõe um sujeito sensível e aberto à sua própria transformação (de suas palavras, idéias, sentimentos, etc.). Assim, o sujeito da experiência faz a experiência de sua própria transformação. 
Segundo esses autores, o retorno sobre nós mesmos supõe uma mudança no sujeito que ativamente assume um lugar exterior para contemplar o outro ou o acontecimento. Ambos os autores apontam que, após a contemplação, entramos em um outro processo que nos possibilita uma mudança, seja porque o sujeito sai dessa relação "enriquecido, isto é, ele não permanece igual a ele mesmo" (Bakhtin, 1993, p. 16), seja porque, a partir de sua experiência, o sujeito formou-se ou transformou-se (Larrosa, 2006). Foram essas questōes que me fizeram refletir acerca da potencialidade de pensarmos na formação como uma relação de provoca-açãa.

\section{Tecendo alguns sentidos...}

Aprendi, estando na escola, que a pesquisa se ia delineando em função do que no cotidiano se apresentava, e não em função das questôes ou dos problemas apontados por mim a priori. As falas da professora mobilizaram-me para a busca de caminhos para desenhar minha prática de pesquisa na escola. Concordo com Garcia (2003), quando considera que a pesquisa vai sendo costurada "de acordo com o que a realidade nos leva a fazer." (p. 2.006).

Quando a professora Mônica questionou-me sobre o sentido de minha entrada na sua sala de aula, "ajudar ou pesquisar", tentei compreender qual o lugar que os sujeitos da escola querem que uma pesquisadora assuma quando entra na escola. $\mathrm{O}$ desenvolvimento da pesquisa na escola permitiu-me perceber a importância da parceria, da colaboração, da interlocução e do diálogo; no caso deste trabalho, com a professora Mônica.

No encontro com as professoras, o excedente de visão delas em relação a mim foi o desencadeador de um processo formativo, porque, após o encontro com elas, quando eu retornava para mim mesma, eu produzia ou construía outros sentidos em relação ao que era ser pesquisadora na escola. Foi possível "fazer-me pesquisadora" no encontro com as professoras. E, assim como o excedente de visão delas foi provocativo em relação a mim, estou considerando que meu excedente de visão em relação a elas também foi desencadeador de um processo formativo para elas, pois, ao voltarem-se para elas mesmas, foi possível que ressignificassem sua prática educativa e o fato de serem professoras. Lembro-me da importância outorgada pela professora Mônica ao meu olhar exterior e de como isso foi provocador para a professora no sentido de refletir sobre sua prática.

A partir da interlocução com a professora e do que as suas perguntas provocaram em mim, enfatizo a importância que tem o outro na corrente da comunicação, no diálogo. O outro me interroga, ele me questiona; é o outro que me faz entrar em um processo para voltar para mim mesma (Larrosa, 2004b). Foi 
nesse "encontro de professora e pesquisadora" que muitos desafios foram colocados e promoveram a reflexão sobre nós mesmas e a reflexão sobre os alunos; sobre as dificuldades enfrentadas no dia-a-dia na escola e também sobre as condições de trabalho na sala de aula e na escola.

Aponto, a seguir, uma construção teórica que foi possível tecer, ao revelar a trama na qual me envolvi como pesquisadora, quando escolhi fazer pesquisa na escola e com a escola. Construir e desenvolver a perspectiva de pesquisar na e com a escola implicou asssumir que essa perspectiva tem como base ou sustento uma trilogia "pesquisa-alteridade-formação" (Chaluh, 2008).

Ao longo do trabalho foi explicitada a relação estabelecida entre a pesquisa e a alteridade. Levando em consideração essa relação, posteriormente ficou evidente que o encontro com o outro, a partir da pesquisa, foi desencadeador de um processo formativo. Nesse sentido, pesquisar na e com a escola, junto com as professoras da escola, desencadeou um processo formativo nelas e em mim. Assim, a partir das consideraçôes da professora, de nossa relação e da pesquisa desenvolvida na escola, foi possível pensar a relação alteridade-formação atrelada à pesquisa.

A experiência de ter sido pesquisadora na escola possibilitou-me viver acontecimentos que me levaram a dizer de um outro sentido tanto da pesquisa como da formação, ambas atreladas à alteridade. Assim, foi possível pensar além da dicotomia ajudar-pesquisar, ao perceber a potencialidade que a pesquisa tem, quando considerada a partir de uma perspectiva dialógica, para a formação de todos aqueles que participam dela - uma formação considerada como uma relação de provoca-ação com o outro; uma relação com o outro como uma provoca-ação formativa (Chaluh, 2008).

\section{Referências bibliográficas}

AMORIM, Marília. Vozes e silêncio no texto de pesquisa em Ciências Humanas. Caderno de Pesquisa, n. 116, p. 7-19, julho 2002.

AMORIM, Marília. A contribuição de Mikhail Bakhtin: a tripla articulação ética, estética e epistemológica. In: FREITAS, M. T.; JOBIM E SOUZA, S.; KRAMER, S. (Org.). Ciências humanas e pesquisa: leitura de Mikhail Bakhtin. São Paulo: Cortez, 2003.

AMORIM, Marília. Opesquisador e seu outro: Bakhtin nas ciências humanas. São Paulo: Musa Editora, 2004.

BAKHTIN, Mikhail. Estética da criação verbal. São Paulo: Martins Fontes, 1992.

BAKHTIN, Mikhail. Para uma filosofia do ato. Tradução de Carlos Alberto Faraco e Cristóvão Tezza, para uso didático e acadêmico, de Toward a philosophy of the act (Austin: University of Texas Press, 1993). Mimeo. (Original de 1926). 
BENJAMIN, Walter. Magia e técnica, arte e politica: ensaios sobre literatura e história da cultura. 7. ed. São Paulo: Editora Brasiliense, 1996. (Obras escolhidas. v.1).

CHALUH, Laura Noemi. Formação e alteridade: pesquisa na e com a escola, 2008. 318p. Tese (Doutorado em Educação) - Faculdade de Educação, Universidade Estadual de Campinas, Campinas, 2008.

CHALUH, Laura Noemi. Leitura e escrita: possibilidades para a reflexão. In:TOLEDO, G.; SOLIGO, R. (Org.) Porque escrever é fazer história. Campinas, SP: Graf. FE, 2005.

FREITAS, Maria Teresa. A abordagem sócio-histórica como orientadora da pesquisa qualitativa. Cadernos de Pesquisa, n. 116, p. 21-39, julho 2002.

FREITAS, Maria Teresa. A perspectiva sócio-histórica: uma visão humana da construção do conhecimento. In: FREITAS, Maria Teresa; JOBIM e SOUZA, Solange; KRAMER, Sonia (Org.). Ciências humanas e pesquisa: leitura de Mikhail Bakhtin. São Paulo: Cortez, 2003a (Coleção questôes da nossa época. v. 107).

FREITAS, Maria Teresa. A pesquisa na perspectiva sócio-histórica: um diálogo entre paradigmas. 2003b. Disponível em: <http://www.anped.org.br/reunioes/26/outrostextos/ semariateresaassuncaofreitas.rtf.>. Acesso em: maio de 2007.

FREITAS, Maria Teresa. Nos textos de Bakhtin e Vygotsky: um encontro possível. In: BRAIT (Org.). Bakhtin, dialogismo e construção do sentido. Campinas: Editora da Unicamp, 1997.

GARCIA, Regina Leite. A difícil arte/ciência de pesquisar com o cotidiano. In: GARCIA, Regina Leite (Org.). Método; métodos; contramétodos. São Paulo: Cortez, 2003.

GERALDI, João Wanderley. A diferença identifica. A desigualdade deforma. Percursos bakhtinianos de construção ética e estética. In: FREITAS, Maria Teresa; JOBIM e SOUZA, Solange; KRAMER, Sonia. (Org.): Ciências humanas e pesquisa: Leituras de Mikhail Bakhtin. São Paulo: Cortez, 2003a. p.39-56.

GERALDI, João Wanderley. Paulo Freire e Mikhail Bakhtin, o encontro que não houve. In: ALMEIDA, N. S. Leitura: um cons/certo. São Paulo: Companhia Editora Nacional, 2003b.

GERALDI, João Wanderley. Encontro na alteridade: um diálogo entre Vigotski e Bakhtin. In: BENITES, Maria. FICHTNER, Bernd; GERALDI, João Wanderley. Transgressões convergentes - Vigotski, Bakhtin e Bateson: coletânea de textos. Campinas, SP: [s.n.], 2005. p. 100-111. (Referência com base nos originais).

GINZBURG, Carlo. Sinais. Raízes de um paradigma indiciário. In: GINZBURG, Carlo. Mitos, emblemas, sinais: morfologia e história. São Paulo: Companhia das Letras, 1989.

JOBIM S SOUZA, Solange. Mikhail Bakhtin e Walter Benjamin: polifonia, alegoria e o conceito de verdade no discurso da ciência contemporânea. In: BRAIT, B. (Org.) Bakhtin, dialogismo e construção do sentido. Campinas, São Paulo: Editora da Unicamp, 1997.

LARROSA, Jorge. Notas sobre a experiência e o saber da experiência. In: GERALDI, Corinta Maria Grisolia; RIOLFI, Claudia Rosa; GARCIA, Maria de Fátima (Org.). Escola viva: elementos para a construção de uma educação de qualidade social. Campinas, SP: Mercado de Letras, 2004a. p.113-132. 
LARROSA, Jorge. Experiencia y alteridad en educación. [Buenos Aires: FLACSO, 2006] Disponível em: <http://virtual.flacso.org.ar/mod/book/print.php?id=3908>. Acesso em: 16 de maio de 2006.

LARROSA, Jorge. Pedagogia profana: danças, piruetas e mascaradas. Tradução de Alfredo Veiga-Neto, 4. ed., 2a imp. Belo Horizonte: Autêntica, $2004 \mathrm{~b}$.

SECRETARIA MUNICIPAL DE EDUCAÇÃO DE CAMPINAS. Educação Municipal investe em formação para reduzir repetência. Notícias da educação, 04 fev. 2004. Disponível em: <http://www.campinas.sp.gov.br/smenet/noticias/noticia_2004_02_04b.htm>. Acesso em 10 de março de 2004.

Recebido em 25 de julho de 2008 e aprovado em 31 de outubro de 2008. 